\title{
Psychomotor Development of Children Born Premature at the Yaounde Gynaeco-Obstetric and Pediatric Hospital (Cameroon)
}

\author{
Séraphin Nguefack ${ }^{1,2}$, Eric G. Ananfack ${ }^{2}$, Evelyn Mah',2, Daniel Kago', Sandra Tatah", \\ F. Puepi Yolande 3 , Dominique Enyama ${ }^{4}$, Diomede Noukeu ${ }^{4}$, Andreas Chiabi ${ }^{1,2}$, \\ Felicité Dongmo Nguefack ${ }^{1,2}$ \\ ${ }^{1}$ Department of Pediatric, Yaoundé Gynaeco-Obstetric and Pediatric Hospital, Yaounde, Cameroon \\ ${ }^{2}$ Departement of Paediatrics, Faculty of Medecine and Biomedical Sciences, University of Yaounde I, Yaounde, Cameroon \\ ${ }^{3}$ Faculty of Health Sciences, University of Buea, Buea, Cameroon \\ ${ }^{4}$ Faculty of Medecine and Pharmaceutical Sciences, University of Dschang, Dschang, Cameroon \\ Email: *seraphin_nguefack@yahoo.fr
}

How to cite this paper: Nguefack, S., Ananfack, E.G., Mah, E., Kago, D., Tatah, S., Yolande, F.P., Enyama, D., Noukeu, D., Chiabi, A. and Nguefack, F.D. (2020) Psychomotor Development of Children Born Premature at the Yaounde Gynaeco-Obstetric and Pediatric Hospital (Cameroon). Open Journal of Pediatrics, 10, 147-158.

https://doi.org/10.4236/ojped.2020.101014

Received: January 25, 2020

Accepted: March 3, 2020

Published: March 6, 2020

Copyright $\odot 2020$ by author(s) and Scientific Research Publishing Inc. This work is licensed under the Creative Commons Attribution International License (CC BY 4.0).

http://creativecommons.org/licenses/by/4.0/ (c) (i) Open Access

\begin{abstract}
Premature infants are at risk for developmental delay. We assessed the psychomotor development of children born before 37 weeks of gestation. Methods: This was a descriptive cross-sectional study conducted in the Pediatric Department of the Yaounde Gynaeco-Obstetric and Pediatric Hospital from January to May 2018. We used the Denver II scale to assess the psychomotor development of children born premature aged 9 months to 6 years. Children born between January 2012 and April 2017 at a gestational age strictly below 37 weeks of gestation were included. Using logistic regression, we searched for perinatal factors associated with abnormalities of psychomotor developmental. Results: We included 50 children in our study, $60 \%$ of whom were boys, giving a sex ratio of 1.5 . The mean age was $25 \pm 19.5$ months. The mean gestational age was $33 \pm 2.2$ weeks and the mean birth weight was $2178.68 \pm$ $748.01 \mathrm{~g}$. The average Developmental Quotient of the population was 108. Six children (12\%) had a global developmental delay (DQ $<70$ ), $22 \%$ of the children had a language delay. Convulsion was associated with motor delay $(\mathrm{OR}=16 ; \mathrm{P}=0.03)$, and pregnancy monitoring a protective factor for language delay $(\mathrm{P}=0.02)$. Conclusion: Improving perinatal care remains a preoccupying issue. The assessment of psychomotor development should be done until early childhood to enable early diagnosis of learning disabilities.
\end{abstract}

\section{Keywords}

Premature Babies, Psychomotor Development, Yaounde, Cameroon 


\section{Introduction}

According to the World Health Organization, 15 million births occur before 37 weeks of gestation in the world, affecting more than one in 10 children, $60 \%$ of whom come from South Asia and Sub-Saharan Africa, and 1 million die from complications of prematurity [1]. In Cameroon, in 2010, the prevalence of premature births at the Yaounde Gyneco-Obstetric and Pediatric Hospital was $10.4 \%[2]$.

In addition to its significant contribution to neonatal mortality, prematurity exposes survivors to long term risks of global developmental delay leading to motor, adaptive and cognitive neurological development disorders, even if the deficits in these areas are subtle [3]. Typically, oxygen deprivation of the fetal brain or acute perinatal inflammation [4] has been implicated. The risk factors for developmental disorders of the premature infant are in reality multiple, combining the intervention of antenatal factors (pre-eclampsia, nutritional insufficiency, toxins, stress or drugs), perinatal (anoxia, chorioamnionitis, deprivation of endogenous protective factors such as growth hormones) and postnatal (respiratory failure and chronic hypoxia, ectopic growth retardation, stress, attachment disorder, drugs (early postnatal corticosteroid therapy)). The prevalence of these disorders is higher the lower the gestational age, the extremely premature ( $<26$ weeks of gestation) having the worst prognosis [5]

In premature babies, the frequency and severity of cerebral palsy and secondary disabilities have decreased in recent years due to progress made in the monitoring of pregnancies and in the management of premature babies (such as antenatal administration to the mother of magnesium sulphate, developmental care and nutrition techniques) [6] [7]. It is estimated that the risks of cerebral palsy, all stages combined, are still around $6 \%$ to $8 \%$ for children born before 33 weeks of gestation (more than $10 \%$ for extremely premature) and $1 \%$ for moderately premature babies against $1 \%$ in the general population [8].

However, for children without major neurological deficit, less severe abnormalities may occur [8]. They affect learning, coordination or fine motor skills, and are grouped under the term of minor neuromotor dysfunction [8].

The aim of our study was to assess psychomotor development in children born prematurely at the Yaounde Gyneco-Obstetric and Pediatric Hospital including gross motor skills, fine motor skills, language and social development.

\section{Patients and Methods}

The study was carried out at the Pediatrics Department of the Yaounde Gynaeco-Obstetric and Pediatric Hospital. From January 1, 2018 to May 31, 2018, we conducted a cross-sectional descriptive study in premature infants coming to consult for their follow-up. A non-probability and consecutive sampling was done, according to the inclusion criteria. We included 50 children aged 9 months to 6 years born before 37 weeks of gestation between January 2012 and April 2017. We included all children born premature, followed in the service and 
aged between 9 months and 6 years. The inclusion was effective after the parents agreed and provided informed parental consent. Any patient whose parent was not consenting and whose age was outside our range was excluded.

We contacted the parents by phone and gave them an appointment. During the consultation, we gave parents a questionnaire concerning the following elements: the socio-demographic characteristics of the mother-child pair (age, place of residence, education of the children, level of education of the mothers, their profession and marital status), history of pregnancy (maternal pathologies, serologies, vaccinations, monitoring of pregnancy), the course of childbirth, the state of the child at birth (gestational age, birth weight, resuscitation at birth, Apgar score, hospital stay for neonatal comorbidities (jaundice, respiratory distress, seizures, anemia, neonatal infections)) and duration of hospital stay. We performed a physical examination of children during which we recorded anthropometric parameters of the infant and assessed their psychomotor development.

This assessment was carried out along the four elements of psychomotor development described in the Denver II test, which were gross motor skills, fine motor skills, language and social development. Our focus was on the child's acquisitions at the time of our assessment.

For each element of the Denver test (language, gross motor skills, fine motor skills, social development), we administered at least three items completely to the left of the line corresponding to the actual age of the child and those across the line. We observed the patient doing the desired item (for example standing, walking, throwing the ball, pedaling a tricycle). If the child was unable to complete the items in the first step, other items were administered to the left of the line until the child passed three consecutive items, then administered the items to the right of his age line until he missed three consecutive items. The ages corresponding to the lines from which the child missed 3 consecutive items represented the developmental age (DA).

At the end, we calculated the development quotient (DQ) which is the ratio of the developmental age (DA) and the actual age (AA) of the patient (DQ = $\mathrm{DA} / \mathrm{AA} \times 100)$, from which the level of development was classified as high (>120), normal (85 - 119), borderline (70 - 84), mild delay (50 - 69), moderate delay (35 - 49), severe delay (20 - 34$)$ and very severe delay $(<20)$.

These variables were analyzed with Statistical Package for Social Science (SPSS) version 22. The qualitative variables were integrated into a simple logistic regression model to find the ORs. A $p$ value $<0.05$ was considered statistically significant for all analyzes.

\section{Results}

During our study, we recruited 80 children, subsequently obtaining parental consent for 50 children, $60 \%$ of whom were boys and $40 \%$ girls, giving a sex ratio of 1.5. The distribution according to the term was as follows: $2 \%$ at 27 weeks of gestation, $28 \%$ between 28 and 32 weeks of gestation and $70 \%$ between 33 and 36 
weeks of gestation with an average gestational age of $33.30 \pm 2.20$ weeks and a birth weight average of $2178 \pm 748 \mathrm{~g}$.

Most of the children seen during consultations belonged to the 12-23 months age group (34\%), with an average age of $25 \pm 19.5$ months. Also, 12 children (24\%) lived in rural areas, 21 (42\%) were the first child and 32 (64\%) were not yet in school. The average age of the mothers interviewed was $29 \pm 5.41$ years, 34 $(68 \%)$ of them were married and $21(42 \%)$ were unemployed (Table 1$)$.

In our study, 32 of the mothers (64\%) had done at least 4 antenatal consultations. We found risk factors for premature delivery in 29 mothers (58\%) including premature and/or prolonged rupture in 24 of them (48\%), eclampsia and pre-eclampsia in 4 mothers (8\%) and diabetes in one mother (2\%). 20 mothers (40\%) had confirmed infections during pregnancy, including malaria in 13 $(26 \%)$ of them and urogenital infection in 4 mothers (8\%) (Table 2).

10 children (20\%) were resuscitated at birth, 26 (52\%) had a duration of hospital stay varying between 7 and 14 days. 34 children (68\%) presented a complication related to prematurity during this stay, $6 \%$ had convulsions, $42 \%$ suspected infection, $12 \%$ jaundice (Table 2 ).

Table 1. General characteristics of the mother-child pair.

\begin{tabular}{|c|c|c|}
\hline & $\mathrm{N}(\%)$ & Mean \pm SD \\
\hline Age group of children & & $25 \pm 19.5$ months \\
\hline [9- 36 months] & $33(66)$ & \\
\hline [3 - 72 months] & $17(34)$ & \\
\hline Sex (\% males) & $30(60)$ & \\
\hline Residence (\% rural) & $12(24)$ & \\
\hline \multicolumn{3}{|l|}{ Rank in family } \\
\hline 1 st & $21(42)$ & \\
\hline 2nd & $14(28)$ & \\
\hline$\geq 3$ rd & $15(30)$ & \\
\hline \multicolumn{3}{|l|}{ Education } \\
\hline None/day care center & $32(64)$ & \\
\hline Nursery school & $13(26)$ & \\
\hline Primary school & $5(10)$ & \\
\hline Age group of mothers & & $29 \pm 5.41$ years \\
\hline$\leq 20-30$ years & $28(56)$ & \\
\hline$>30$ years & $22(44)$ & \\
\hline \multicolumn{3}{|l|}{ Level of education of mothers } \\
\hline Not educated & $1(2)$ & \\
\hline Primary & $9(18)$ & \\
\hline Secondary & $25(50)$ & \\
\hline Higher education & $15(30)$ & \\
\hline Marital status (\%married) & $34(68)$ & \\
\hline \multicolumn{3}{|l|}{ Profession of mothers } \\
\hline Student & $2(4)$ & \\
\hline Unemployed & $21(42)$ & \\
\hline
\end{tabular}


Table 2. Pre, per and postnatal characteristics.

\begin{tabular}{|c|c|c|}
\hline Characteristics & $\%(\mathrm{n})$ & Mean \pm SD \\
\hline Number of ANCs $(\geq 4)$ & $64(32)$ & \\
\hline \multicolumn{3}{|l|}{ Maternal pathologies (\% yes) } \\
\hline Premature rupture of membranes & $34(17)$ & \\
\hline Prolonged rupture of membranes & $14(7)$ & \\
\hline Eclampsia/pre-eclampsia & $8(4)$ & \\
\hline Diabetes & $2(1)$ & \\
\hline Malaria & $26(13)$ & \\
\hline Urogenital infections & $8(4)$ & \\
\hline HIV infection & $6(3)$ & \\
\hline Gestational age (GA) & & $33.30 \pm 2.20$ \\
\hline$[26-28]$ & $2(1)$ & \\
\hline$[28-32]$ & $28(14)$ & \\
\hline$[33-36]$ & $70(35)$ & \\
\hline Birth weight (g) & & $2178 \pm 748$ \\
\hline$[1000-1500[$ & $12(6)$ & \\
\hline$[1500-2000[$ & $28(14)$ & \\
\hline$[2000-3000[$ & $52(26)$ & \\
\hline$[3000-4500]$ & $8(4)$ & \\
\hline Resuscitation (\% yes) & $20(10)$ & \\
\hline \multicolumn{3}{|l|}{ Duration of hospital stay (days) } \\
\hline$<7$ & $18(9)$ & \\
\hline$[7-14]$ & $52(26)$ & \\
\hline$>14$ & $30(15)$ & \\
\hline Pathologies during the stay (\% yes) & $68(34)$ & \\
\hline Convulsions & $6(3)$ & \\
\hline Jaundice & $14(7)$ & \\
\hline Infection & $42(21)$ & \\
\hline Asphyxia & $6(3)$ & \\
\hline
\end{tabular}

\subsection{Distribution of the Level of Global Development}

According to the development quotient, the children were divided into different categories (Table 3). Six patients (12\%) had a global delay in psychomotor development, half of which was a mild delay. In the analysis of the various elements of psychomotor development, 11 (22\%) children showed a language delay, $7(14 \%)$ a delay in gross motor skills, $6(12 \%)$ a delay in fine motor skills and $9(18 \%)$ a social development delay (Table 3$)$.

\subsection{Factors Associated with Developmental Delay}

After integration into a logistic regression model, no association was found between the different gestational age groups, birth weight, maternal pathologies 
Table 3. Classification of level of development by item.

\begin{tabular}{cccccc}
\hline Level & $\begin{array}{c}\text { Global psychomotor } \\
\text { development }\end{array}$ & Gross motor & Fine motor & Language & $\begin{array}{c}\text { Social } \\
\text { development }\end{array}$ \\
\hline High level & N (\%) & N (\%) & N (\%) & N (\%) & N (\%) \\
Normal & $26(4)$ & $3(6)$ & $2(4)$ & $2(4)$ & $4(8)$ \\
Borderline & $16(32)$ & $34(68)$ & $27(54)$ & $22(44)$ & $22(44)$ \\
Mild delay & $3(6)$ & $6(12)$ & $15(30)$ & $15(30)$ & $15(30)$ \\
$\begin{array}{c}\text { Moderate } \\
\text { delay }\end{array}$ & $1(2)$ & $4(8)$ & $3(6)$ & $7(14)$ & $4(8)$ \\
$\begin{array}{l}\text { Severe delay } \\
\text { Very severe }\end{array}$ & $2(4)$ & $0(0)$ & $1(2)$ & $1(2)$ & $3(6)$ \\
$\begin{array}{c}\text { delay } \\
\text { Total }\end{array}$ & 0 & $0(0)$ & $1(2)$ & $1(2)$ & $0(0)$ \\
\hline
\end{tabular}

during pregnancy and all elements of psychomotor development. Convulsion in the neonatal period was associated with gross motor skills delay $(p=0.03 ; \mathrm{OR}=$ $16 \mathrm{CI}[1.3-403.4])$. Proper monitoring of pregnancy protected against language delay $(P=0.02 \mathrm{OR}=0.07)($ Table 4$)$.

\section{Discussion}

In our study, the majority (88\%) of the children who came for follow-up had normal development. These results are similar to those of Ballot et al. [9], who found that $15.1 \%$ of their population had a psychomotor index $<70$; and $33.3 \%$ were borderline. For children in the EPIPAGE cohort, free from severe neurological or sensory impairment, there is a higher proportion of intellectual impairment in premature babies [5]. Indeed, the risk of such a deficiency (QD < 70 ) is $8 \%$ for those under 33 weeks of gestation compared to $3 \%$ in children born at term (with extremes of $14 \%$ for those under 28 weeks of gestation). Concerning more moderate cognitive deficits (QD between 70 and 84 ), the figures are $16 \%$ for $24-28$ weeks of gestation, $21 \%$ at $29-30$ weeks of gestation, $17 \%$ at 31 32 weeks of gestation against only $7 \%$ at term [10]. In the Epicure study conducted in the United Kingdom and Ireland in 1995, children under the age of 25 weeks of gestation, was monitored by administering the $\mathrm{K}-\mathrm{ABC}$ test at 6 years and were compared with a group of children born at term [11]. In general, $40 \%$ of premature babies showed a moderate to severe deficit versus $1.3 \%$ of controls born at term. The most remarkable difficulties concerned mathematics and reading and mainly affected boys (special education or tutoring) [11].

We discovered that $14 \%$ of children had gross motor skills delay. None of them presented with severe motor disorders (cerebral palsy). In the French cohorts, the frequency and severity of cerebral palsy and secondary handicaps in premature babies have decreased in recent years due to the progress made in the monitoring of pregnancies and in their management (antenatal administration of magnesium sulfate to the mother, developmental care and nutrition 
Table 4. Factors associated with developmental delay.

\begin{tabular}{|c|c|c|c|c|c|c|c|c|c|c|}
\hline Characteristics & $\begin{array}{l}\text { Gross motor } \\
\text { delay }(n=)\end{array}$ & $p$ & $\begin{array}{l}\text { Fine motor } \\
\text { delay }(n=6)\end{array}$ & $p$ & $\begin{array}{c}\text { Social } \\
\text { development } \\
\text { delay }(n=9)\end{array}$ & $p$ & $\begin{array}{l}\text { Speech } \\
\text { delay } \\
(\mathrm{n}=11)\end{array}$ & $p$ & $\begin{array}{c}\text { Global } \\
\text { psychomotor } \\
\text { delay }(n=6)\end{array}$ & $p$ \\
\hline & $\mathrm{n}(\%)$ & & $\mathrm{n}(\%)$ & & $\mathrm{n}(\%)$ & & $\mathrm{n}(\%)$ & & $\mathrm{n}(\%)$ & \\
\hline \multicolumn{11}{|l|}{ Gestational age (GA) } \\
\hline$[27-31]$ & $1(14.3)$ & 0.7 & $1(16.7)$ & 0.9 & $1(11.1)$ & 0.5 & $2(18.2)$ & 0.9 & 0 & 0.9 \\
\hline$[32-33]$ & $5(71.4)$ & 0.8 & $2(33.3)$ & 0.6 & $4(44.4)$ & 0.1 & $4(36.4)$ & 0.3 & $2(33.3)$ & 0.6 \\
\hline$[34-36]$ & $4(57.1)$ & 0.9 & $3(50)$ & 0.7 & $4(44.4)$ & 0.4 & $5(45.5)$ & 0.4 & $4(66.7)$ & 0.5 \\
\hline Maternal pathologies (yes) & $2(28.6)$ & 0.4 & 0 & 0.9 & $4(44.4)$ & 0.8 & $3(27.3)$ & 0.2 & $1(16.7)$ & \\
\hline Resuscitation at birth (yes) & $3(42.9)$ & 0.12 & $1(16.7)$ & 0.8 & $4(44.4)$ & 0.05 & $4(36.4)$ & 0.1 & $3(50.0)$ & 0.06 \\
\hline \multicolumn{11}{|l|}{ Birth weight (g) } \\
\hline$[1000-1500[$ & $1(14.3)$ & 0.8 & $1(16.7)$ & 0.5 & $1(11.1)$ & 0.5 & $2(18.2)$ & 0.5 & $0(0.0)$ & 0.5 \\
\hline [1500 - 2000[ & $1(14.3)$ & 0.3 & $1(16.7)$ & 0.5 & $2(22.2)$ & 0.5 & $1(9.1)$ & 0.5 & $1(16.7)$ & 0.5 \\
\hline$[2000-3000[$ & $4(57.1)$ & 0.6 & $3(50)$ & 0.5 & $5(55.6)$ & 0.5 & $7(63.6)$ & 0.5 & $3(50.0)$ & 0.5 \\
\hline$[3000-4500[$ & $1(14.3)$ & 0.5 & $1(16.7)$ & 0.5 & $1(11.1)$ & 0.5 & $1(9.1)$ & 0.5 & $2(33.3)$ & 0.5 \\
\hline \multicolumn{11}{|l|}{ Neonatal pathologies } \\
\hline Convulsion & $2(28.6)^{\star}$ & 0.03 & $1(16.7)$ & 0.2 & $1(11.1)$ & 0.4 & $1(9.1)$ & 0.6 & $1(16.7)$ & 0.2 \\
\hline Jaundice & $2(28.6)$ & 0.1 & $2(33.3)$ & 0.1 & $2(22.2)$ & 0.3 & $2(18.2)$ & 0.4 & $2(33.3)$ & 0.1 \\
\hline Infection & $3(42.9)$ & 0.9 & $3(50)$ & 0.6 & $4(36.4)$ & 0.8 & $2(18.2)$ & 0.09 & $2(33.3)$ & 0.6 \\
\hline Asphyxia & 0 & 0.9 & 0 & 0.9 & $2(18.2)$ & 0.05 & $4(36.4)$ & 0.6 & $1(16.7)$ & 0.2 \\
\hline Monitored pregnancy & & & & & & & $8(72.7)^{*}$ & 0.02 & & \\
\hline
\end{tabular}

technique) [6] [7]. These cohorts showed that the risk of cerebral palsy is around $6 \%$ to $8 \%$ for children born before 33 weeks of gestation (more than $10 \%$ for the extremely premature) and $1 \%$ for moderately premature [8]. In our study, proper monitoring of pregnancy was a factor associated with favorable language development. The most affected psychomotor development element in our series was language with $22 \%$ of language delay. On the other hand, Nepomnyaschy et al. in the USA in 2011 [12] found a preponderance of social development delay, while Eickmann et al. in 2012 [13] in Brazil found motor skills to be the most affected element. The preponderance of language delay in our population could be explained by the fact that in our African societies there is a harmony between the child and its mother which allows it by its gestures, attitudes, cries, and facial expressions, to be understood and have its needs satisfied without having to develop a socialized language. This result can be compared to that of Ballot et al. [9] though in different proportions, as they found that the developmental element most affected was language (9.4\%), followed by cognition (8.5\%) and motor skills (7.6\%). It is difficult to accurately assess the incidence of language impairment in premature infants due to discordant results from different studies. However, the acquisition of a good level of development of the oral language is 
essential, in the sense that it partly conditions the future school acquisitions. Also, the presence of even subtle language difficulties can harm a child's social relationships. Language impairments or poorer verbal skills have often been observed in very premature infants [14].

According to a Swedish study [15], babbling seems more often absent in premature babies, and stuttering occurs more frequently. According to Wolke and Meyer, the scores for exercises evaluating language are lower for premature infants at 6 years of age, especially for syntax and detection of semantically incorrect sentences, while receptive language and vocabulary seem less affected [16].

In France, a more recent prospective study compared the development of oral language at the age of 5 years of 55 children born very premature, without cerebral palsy, with that of children born at term, matched by sex and age. One of the important points is that for $76 \%$ of these children, no language disorder was known at the time, although found for $1 / 3$ of them after testing was done [17]. The environmental factor seems able to partially compensate for these disorders since there are fewer difficulties in these two areas within a family of high socio-cultural status [17]. In contrast, the group of premature infants did not have more vocabulary, semantic or morphosyntax deficits than the term infants. These disorders, though varied and complex, deserve to be screened in order to prevent learning disabilities, especially the failure to learn to write. A delay in the development of oral language, specifically for expression and reception, is frequent in premature babies [18]. Abnormalities in speech production and in the length of utterance evaluated by the IFDC test (French inventories of communicative development) testify to a delay in language at 2 years. At 6 years of age, language development disorders in premature infants mainly concern phonology and morpho-syntactic understanding [19]. Understanding does not improve over time in the absence of specific care. In adolescents, reading comprehension, reading speed and verbal memory are directly linked to prematurity after controlling the performance intelligence quotient and socio-cultural status [20]. For language, the premature infant uses more complex neural circuits than the normal full-term infant, including more developed left Wernicke-Broca connections and left-right inter-hemispheric connections [21].

The Denver II test used in our study, which can be easily carried out routinely during consultation by doctors, is specific for screening for these disorders. But once discovered, other language tests should be used to further assess these language disorders.

Twenty percent (20\%) of our population had a history of resuscitation at birth. This notion of resuscitation at birth, just as perinatal asphyxia, was associated with social development delay, albeit marginally significant. Furthermore, perinatal asphyxia was also associated, but not significantly, with language delay $(P=0.09)$. This result is comparable to that of Ballot et al who found that $34 \%$ of premature babies who have been resuscitated at birth have a cognitive delay [9]. Also, Eickmann et al. found that perinatal asphyxia was associated with an average motor skills score of less than 100 [13]. This could be explained by the fact 
that fetal asphyxia is accompanied by an increased risk of anoxic-ischemic encephalopathy and sequelae. It has been clearly demonstrated that a premature fetus risks developing metabolic acidosis more quickly and in a more severe form than a full-term fetus. Indeed, the ability of the fetus to adapt to different anoxic-ischemic attacks during asphyxia depends largely on its reserves, thus its trophicity and its term [9]. Perinatal neurological pathologies of hypoxic-ischemic and/or hemorrhagic origin vary according to gestational age, as do areas of brain susceptibility. The major associated disabilities are cerebral palsy $18 \%$ from 24 to 26 weeks of gestation, $12 \%$ to $13 \%$ from 27 to 29 weeks of gestation, $4 \%$ to $8 \%$ from 30 to 32 weeks of gestation; intellectual disability (IQ < 70) $13 \%$ at 24 weeks of gestation, $8 \%$ at 32 weeks of gestation. Late preterm infants, 34 to 36 weeks of gestation (6\% of births) can also have longer-term sequelae, although less severe and therefore diagnosed later.

We found an 18\% delay in social development. Hyperactivity and disturbances of emotional behavior are frequently observed in the premature infant. They were approximately twice as frequent at 8 years in the group of premature infants in the first EPIPAGE study compared to the group of children born at term [20]. They are significantly less frequent when the mother received antenatal magnesium sulphate in the PREMAG cohort, which is not systematic in our context [22].

We found a $12 \%$ delay in fine motor skills. Minor neuromotor disorders (tone disorders, postural instability, impaired coordination and fine motor skills) are much more common than cerebral palsy, affecting nearly 5 in 2 children in the EPIPAGE study [5]. At school age, these motor skills disorders are still observed in $40 \%$ of children born before 37 weeks of gestation. In our study, this could be underestimated because very few parents return for follow-up after the child has attained catch up in growth or acquired gross motor skills, hence the need to create a network that would make it possible to monitor these children up to school age.

Monitoring of pregnancy has been identified as a protective factor for language delay. On the other hand, vitamin supplementation in the diet of the child could also be a protective factor $(\mathrm{OR}=0.1 ; P=0.09)$. This result could be explained by the mechanism of action of vitamins in cognitive performance through their methylation functions in the nervous system [23]. The history of neonatal resuscitation was the only factor found to be potentially associated with a delay in global psychomotor development $(\mathrm{OR}=5.2 ; P=0.09)$. Furthermore, no statistically significant association was found between gestational age, birth weight and psychomotor development. This result can be superimposed on that of Ballot et al in South Africa in 2012 [9] who found that gestational age and birth weight were not statistically associated with the psychomotor development of their premature babies.

In our study, as factors associated with delayed psychomotor development, the history of neonatal convulsion multiplied by 16 the risk of developing a gross motor skills delay $(\mathrm{OR}=16 ; P=0.03$ ). This could be explained by the fact that 
convulsions cause the destruction of neurons. Indeed, at the cellular level, the seizures result in repeated depolarizations which induce an excessive release of glutamate in all the areas concerned. Attachment of glutamate to its main post-synaptic receptor, the NMDA receptor, causes an excessive increase in intracellular calcium, then ensues activation of the calcium-dependent enzymes cascade, leading to excitotoxicity which can lead to cell death [24]. The risk of disability increases in the presence of complications such as anoxia, intracranial hemorrhage, hypoglycemia, indirect hyperbilirubinemia and meningitis.

Psychomotor and language development must, therefore, be monitored very carefully. Multidisciplinary rehabilitation care (physiotherapy, occupational therapy, speech therapy) must be started early if necessary.

\section{Conclusion}

In our monitored premature babies, $12 \%$ have a delay in global psychomotor development. Convulsion in premature infants is a risk factor for motor delay and monitoring of pregnancy is a protective factor against language delay. It is therefore important to improve the monitoring of pregnant women and that of premature children in the short and long term. The reduction of the influence of prematurity on psychomotor development requires rigorous and very early monitoring of premature babies to detect psychomotor development anomalies in time and take care early. The biggest challenge for perinatal care is the increasing the number and quality of prenatal consultations, the treatment of infections during pregnancy and strengthening the prevention of malaria in our environment.

\section{Conflicts of Interest}

The authors declare no conflicts of interest regarding the publication of this paper.

\section{References}

[1] Blencowe, H., Krasevec, J., de Onis, M., Black, R.E., An, X., Stevens, G.A., et al. (2019) National, Regional, and Worldwide Estimates of Low Birthweight in 2015, with Trends from 2000: A Systematic Analysis. The Lancet Global Health, 7, e849-e860. https://doi.org/10.1016/S2214-109X(18)30565-5

[2] Chiabi, A., Mah, E.M., Mvondo, N., Nguefack, S., Mbuagbaw, L., Kamga, K.K., et al. (2013) Risk Factors for Premature Births: A Cross-Sectional Analysis of Hospital Records in a Cameroonian Health Facility. African Journal of Reproductive Health, $17,77-83$.

[3] Moster, D., Lie, R.T. and Markestad, T. (2008) Long-Term Medical and Social Consequences of Preterm Birth. The New England Journal of Medicine, 359, 262-273. https://doi.org/10.1056/NEJMoa0706475

[4] Marret, S., Vanhulle, C. and Laquerriere, A. (2013) Pathophysiology of Cerebral Palsy. In: Handbook of Clinical Neurology, Vol. 111, Elsevier, Amsterdam, 169-176. https://doi.org/10.1016/B978-0-444-52891-9.00016-6

[5] Larroque, B., Ancel, P.Y., Marret, S., Marchand, L., Andre, M., Arnaud, C., et al. 
(2008) Neurodevelopmental Disabilities and Special Care of 5-Year-Old Children Born before 33 Weeks of Gestation (the EPIPAGE study): A Longitudinal Cohort Study. The Lancet, 371, 813-820. https://doi.org/10.1016/S0140-6736(08)60380-3

[6] Doyle, L.W., Crowther, C.A., Middleton, P. and Marret, S. (2009) Antenatal Magnesium Sulfate and Neurologic Outcome in Preterm Infants: A Systematic Review. Obstetrics \& Gynecology, 113, 1327-1333. https://doi.org/10.1097/AOG.0b013e3181a60495

[7] Himmelmann, K., Hagberg, G. and Uvebrant, P. (2010) The Changing Panorama of Cerebral Palsy in Sweden. X. Prevalence and Origin in the Birth-Year Period 1999-2002. Acta Paediatrica, 99, 1337-1343. https://doi.org/10.1111/j.1651-2227.2010.01819.x

[8] Marret, S., Chollat, C., de Quelen, R., Pinto Cardoso, G., Abily-Donval, L., Chadie, A., et al. (2015) Course and Neurological/Behavioral Development of Preterm Children. Acta Paediatrica, 22, 195-202. https://doi.org/10.1016/j.arcped.2014.11.016

[9] Ballot, D.E., Potterton, J., Chirwa, T., Hilburn, N. and Cooper, P.A. (2012) Developmental Outcome of Very Low Birth Weight Infants in a Developing Country. BMC Pediatrics, 12, 11. https://doi.org/10.1186/1471-2431-12-11

[10] Marret, S. (2008) La prise en charge à 5 ans de l'enfant prématuré avec séquelles neuro-développementales est-elle optimum en France? À propos de l'étude EPIPAGE. Archives de Pédiatrie, 15, 595-597. https://doi.org/10.1016/S0929-693X(08)71845-1

[11] Faber, C. (2010) Devenir à l'âge de onze ans des très grands prématurés de la cohorte Epicure. Médecine et Enfance, 30, 334-336.

[12] Nepomnyaschy, L., Hegyi, T., Ostfeld, B.M. and Reichman, N.E. (2012) Developmental Outcomes of Late-Preterm Infants at 2 and 4 Years. Maternal and Child Health Journal, 16, 1612-1624. https://doi.org/10.1007/s10995-011-0853-2

[13] Eickmann, S.H., de Araújo Malkes, N.F. and de Carvalho Lima, M. (2012) Psychomotor Development of Preterm Infants Aged 6 to 12 Months. Sao Paulo Medical Journal, 130, 299-306. https://doi.org/10.1590/S1516-31802012000500006

[14] Larroque, B. (2004) Les troubles du développement des enfants grands prématurés mesurés à l'âge scolaire Revue de la littérature. Journal de Gynécologie Obstétrique et Biologie de la Reproduction, 33, 475-486.

https://doi.org/10.1016/S0368-2315(04)96560-X

[15] Jennische, M. and Sedin, G. (1999) Speech and Language Skills in Children Who Required Neonatal Intensive Care: Evaluation at $6.5 \mathrm{y}$ of Age Based on Interviews with Parents. Acta Paediatrica, 88, 975-982. https://doi.org/10.1111/j.1651-2227.1999.tb00193.x

[16] Wolke, D. and Meyer, R. (1999) Cognitive Status, Language Attainment, and Prereading Skills of 6-Year-Old Very Preterm Children and Their Peers: The Bavarian Longitudinal Study. Developmental Medicine and Child Neurology, 41, 94-109. https://doi.org/10.1017/S0012162299000201

[17] Charollais, A., Stumpf, H., Beaugrand, D., Lemarchand, M., Radi, S., Pasquet, F., et al. (2010) Évaluation à 6 ans du langage de l'enfant né grand prématuré sans paralysie cérébrale: Étude prospective de 55 enfants. Archives de Pédiatrie, 17, 1433-1439. https://doi.org/10.1016/j.arcped.2010.06.012

[18] Blond, M.H., Castello-Herbreteau, B., Ajam, E., Lecuyer, A.I., Fradet, A., Patat, F., et al. (2003) Devenir médical, cognitif et affectif à l'âge de quatre ans des prématurés indemnes de handicap sévère. Étude prospective cas-témoins. Archives de Pédiatrie, 10, 117-125. https://doi.org/10.1016/S0929-693X(03)00307-5 
[19] Burguet, A., Monnet, E., Roth, P., Hirn F., Vouaillat, C., Lecourt-Ducret, M., Fromentin, C., et al. (2000) Devenir neurodéveloppemental à cinq ans des prématurés nés avant 33 semaines d'aménorrhée et indemnes d'infirmité motrice d'origine cérébrale. Archives de Pédiatrie, 7, 357-368.

https://doi.org/10.1016/S0929-693X(00)88830-2

[20] Ancel, P.Y., Bonnier, C., Burguet, A., Combier, E., Estournet-Mathiaud, B., Gautheron, V., et al. (2004) Déficiences et handicaps d'origine périnatale: Dépistage et prise en charge. Les Editions Inserm, $376 \mathrm{p}$.

[21] Berkowitz, G.S. (1993) Epidemiology of Preterm Birth. Epidemiologic Reviews, 15, 414-443. https://doi.org/10.1093/oxfordjournals.epirev.a036128

[22] Chollat, C., Le Doussal, L., de la Villeon, G., Provost, D. and Marret, S. (2017) Antenatal Magnesium Sulphate Administration for Fetal Neuroprotection: A French National Survey. BMC Pregnancy and Childbirth, 17, 304.

https://doi.org/10.1186/s12884-017-1489-Z

[23] Ancel, P.Y., Saurel-Cubizolles, M.J., Di Renzo, G.C., Papiernik, E. and Breart, G. (1999) Very and Moderate Preterm Births: Are the Risk Factors Different? British Journal of Obstetrics and Gynaecology, 106, 1162-1170. https://doi.org/10.1111/j.1471-0528.1999.tb08142.x

[24] Volpe, J.J. (2009) Brain Injury in Premature Infants: A Complex Amalgam of Destructive and Developmental Disturbances. The Lancet Neurology, 8,110-124. https://doi.org/10.1016/S1474-4422(08)70294-1 